\section{Efficient Somatic Embryogenesis and Plant Regeneration from Immature Embryos of Tapiscia sinensis Oliv., an Endemic and Endangered Species in China}

Yuyu Wang, Faju Chen, Yubing Wang, Xiaoling Li, and Hongwei Liang ${ }^{1}$ Biotechnology Research Center, Hubei Key Laboratory of Natural Products Research and Development, China Three Gorges University, Yichang, Hubei, China 443002

Additional index words. Tapiscia sinensis Oliv., immature embryo, somatic embryogenesis, histocytology

\begin{abstract}
High-frequency somatic embryogenesis and plant regeneration were achieved from immature cotyledonary-stage embryos in the endangered plant, Tapiscia sinensis Oliv. Plant growth regulators with different concentrations and combinations on embryogenesis capacity were studied. The optimal explants for in vitro somatic embryogenesis were immature embryos in $T$. sinensis. A high callus induction rate of $100 \%$ was achieved on Murashige and Skoog (MS) basal medium supplemented with 1.0 $\mathrm{mg} \cdot \mathrm{Ll}^{-1}$ 2,4-dichlorophenoxyacetic acid (2,4-D) and $0.5 \%(\mathrm{w} / \mathrm{v})$ activated charcoal. Alternatively, a high induction rate $(\mathbf{9 6 . 1 6 \%}$ ) of somatic embryogenesis was obtained on MS basal medium supplemented with the combination of $0.05 \mathrm{mg} \cdot \mathrm{L}^{-1} \alpha$-naphthaleneacetic acid (NAA) and $0.2 \mathrm{mg} \cdot \mathrm{L}^{-1}$ 6-benzylaminopurine (6-BA), and somatic embryos proliferated fastest on the mentioned medium supplemented with $0.5 \%(\mathrm{w} / \mathrm{v})$ activated charcoal and $3 \%$ (w/v) sucrose, inoculation of explants proliferating 21 times in the 23-day subculture. Of the 100 plantlets transferred to field after the acclimation, $95(95 \%)$ survived. Based on the histocytological observations, the development of somatic embryos was similar to that of zygotic embryos. There were two accumulation peaks of starch grains in the embryogenic calli and in the globular-stage embryos, both closely related to the energy supply, and the embryoids were of multicelluar origin.
\end{abstract}

Tapiscia sinensis Oliv., one of the rare species in China, belongs to the genus Staphylea, family Staphyleaceae. It has not only significant scientific value for the investigation of the origin of the semitropical flora of China, and the phylogenesis of the family Staphyleaceae for its characteristics of the ancient origin, but also a promising ornamental species because of its beautiful flowers and tree form. It is also an excellent plant in afforestation because of its rapid growth habit. This species has a very narrow distribution range in southwestern China and regenerate natural community by seedling. However, natural regeneration capacity of the species is weak because of its low seed setting rate and poor seedling viability under natural conditions (Sun and Liu, 2004). The species takes 17 months to complete the sexual reproductive cycle from zygote initiation to

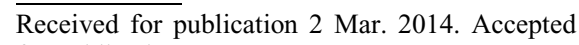
for publication 27 Aug. 2014.

The authors gratefully acknowledge the financial support of the "Five-twelfth" National Science and Technology Support Program (2013BAD03B03) and of Nature Science Foundation of Hubei Province (2012FFB03806).

${ }^{1}$ To whom reprint requests should be addressed; e-mail lianghwcn@aliyun.com.
Reserve in Hubei Province, China (Seed of the species mature in September in Hubei Province.). The immature seeds were washed in $\approx 250 \mathrm{~mL}$ water containing two drops of Tween-20 and then surface-disinfected in $75 \%(\mathrm{v} / \mathrm{v})$ ethanol for $1 \mathrm{~min}$. They were soaked in $0.1 \%(\mathrm{w} / \mathrm{v}) \mathrm{HgCl}_{2}$ solution plus two drops of Tween-20 per $100 \mathrm{~mL}$ for 10 min followed by washing five times with sterile water and soaked in sterile water overnight at $4{ }^{\circ} \mathrm{C}$ to soften the seedcoats. The hard seedcoats were removed mechanically. The decoated seeds were rinsed five times with sterile water then disinfected with $0.1 \%(\mathrm{w} / \mathrm{v}) \mathrm{HgCl}_{2}$ solution for $5 \mathrm{~min}$ and rinsed with sterile water five times, and then the immature embryo of the decoated seeds was placed on the culture medium. The cultures were incubated at $25 \pm 2{ }^{\circ} \mathrm{C}$ under a 16/8-h (light/dark) photoperiod with illumination by white fluorescent light with an intensity of $50 \mu \mathrm{mol} \cdot \mathrm{m}^{-2} \cdot \mathrm{s}^{-1}$.

Callus induction. The immature embryo explants were cultured on MS basal medium supplemented with 2,4-D and in combination with activated charcoal to induce embryogenic calli. Different concentrations of 2,4-D $\left(0.1,0.5,1.0\right.$, and $\left.2.0 \mathrm{mg} \cdot \mathrm{L}^{-1}\right)$ and activated charcoal $(0 \%, 0.05 \%, 0.1 \%, 0.5 \%$, and $1.0 \%$ $\mathrm{w} / \mathrm{v})$ were tested for their effect on the initial callus induction. The rate of callus induction was measured after $20 \mathrm{~d}$. Eight petri dishes for each treatment combination were prepared. On average, 30 explants were cultured to each petri dish, and each treatment was replicated three times.

Differentiation and induction of somatic embryos. Calli, induced from explants after cultured for $20 \mathrm{~d}$, were transferred to new MS culture medium with 6 -BA $(0.1,0.2,0.5$, and $\left.1.0 \mathrm{mg} \cdot \mathrm{L}^{-1}\right)$ and NAA $(0,0.01,0.05$, and 0.1 $\mathrm{mg} \cdot \mathrm{L}^{-1}$ ) and different concentrations of sucrose $(0.00 \%, 1.50 \%, 3.00 \%, 6.00 \%$, and $9.00 \%$ ) to develop somatic embryogenesis. Each treatment consisted of five petri dishes and 20 calli were inoculated to each petri dish, and all treatments were repeated three times. After 19-d culture, somatic embryos emerged and the embryogenesis rate was counted. Then, the somatic embryos were cultured on the growth regulator-free MS culture medium to allow the development of plantlets. The induction frequency of somatic embryogenesis was calculated as follows: the number of explants that induced somatic embryos divided by the total number of explants.

The growth of embryogenic callus was also evaluated. After weighing, the calli was cultured on embryo induction medium (which was screened out form the previous step) supplemented with different concentrations of glucose, and the inoculum was weighted again after 23-d culture. Multiplication rate was counted and presented as the mean \pm SD. Each treatment consisted of five petri dishes and 0.85 to $0.90 \mathrm{~g}$ calli were inoculated to each petri dish, and all experiments were repeated three times.

The basal culture medium used for somatic embryogenesis induction was MS medium (Murashige and Skoog, 1962) supplemented 
with 3\% (w/v) sucrose and solidified by $0.8 \%$ (w/v) agar (National Pharmaceutical Group Corporation, Shanghai, China). The medium was adjusted to $\mathrm{pH} 6.0$ before autoclaving at $0.11 \mathrm{MPa}$ and $121^{\circ} \mathrm{C}$ for $20 \mathrm{~min}$.

Histology. Embryogenic tissues were collected during embryonic development of somatic embryos and were fixed in FAA solution (formalin:acetic acid:absolute ethanol:distilled water of 5:5:45:45, v/v/v/v) for $24 \mathrm{~h}$ at room temperature for fixation, then dehydrated in a graded ethanol series $(70 \%$, $85 \%, 95 \%$, and $100 \%, \mathrm{v} / \mathrm{v}$ ) and embedded in paraffin. Sections were cut 6 to $8 \mu \mathrm{m}$ thin with a rotary microtome, mounted onto glass slides, and then stained with Periodic acidSchiff. At the end, they were observed and photographed with a photomicroscope (Nikon 80i, Japan).

Statistical analysis. The induction percentages were transformed into arcsine values before analysis, and then data were analyzed by analysis of variance to detect significant differences between means using SPSS V11.5 software (IBM, Chicago, IL). Means differing significantly were compared using Duncan's multiple range test at the 5\% probability level. Variability around the mean was represented as $\pm \mathrm{SD}$.

\section{Results}

Callus induction. Explants of immature embryos, cultured on the growth regulatorfree culture medium or the medium containing $0.1 \mathrm{mg} \cdot \mathrm{L}^{-1} 2,4-\mathrm{D}$, largely formed seedlings rather than calli. Calli were induced from the explants of immature embryos on MS medium with 2,4-D $(0.5,1.0,2.0$ $\left.\mathrm{mg} \cdot \mathrm{L}^{-1}\right)$. On the second day after inoculation, the folded cotyledons of immature embryos enlarged and their hypocotyls expanded. The expansion continued until white calli appeared on the seventh day (Fig. 1A). The calli turned from white to black after $10 \mathrm{~d}$ (Fig. 1B). These black calli were fragile and grew slowly. The induction frequency of calli varied with changes in the 2,4-D concentration. There were statistically significant differences among those experimental treatments; the treatment with 2,4-D $\left(1.0 \mathrm{mg} \cdot \mathrm{L}^{-1}\right)$ resulted in the highest induction rate, up to $64.67 \%$ (Table 1). However, there were no large differences in morphology and mass growth of calli formed on different culture media.

Explants of immature embryos were cultured on MS basal medium supplemented with 2,4-D (1.0 mg. $\left.\mathrm{L}^{-1}\right)$ and different concentrations of activated charcoal $(0.05 \%$, $0.1 \%, 0.5 \%$, and $1.0 \%$ ). After $20 \mathrm{~d}$ of culture, the results revealed that activated charcoal had a marked effect on callus induction. The $0.5 \%$ activated charcoal sharply increased the induction rate to almost $100 \%$ (Table 2), whereas it was only $64.67 \%$ without activated charcoal.

Somatic embryogenesis. The calli developed for $20 \mathrm{~d}$ from the explants of immature embryos were subcultured on MS basal medium supplemented with 2,4-D. It was found that their color turned to black and
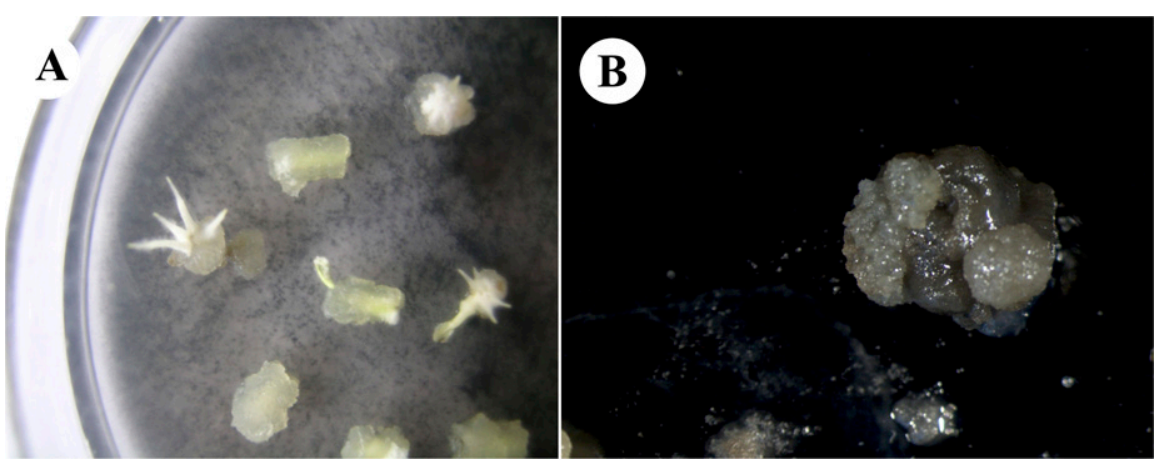

Fig. 1. Various calli from immature embryos of Tapiscia sinensis. (A) Callus from immature embryos. (B) Callus turned from white to black $(\times 8)$.

Table 1. Effect of 2,4-D concentrations on callus induction in Tapiscia sinensis. ${ }^{2}$

\begin{tabular}{lcc}
\hline $\begin{array}{l}\text { Concentrations of } \\
2,4-\mathrm{D}\left(\mathrm{mg} \cdot \mathrm{L}^{-1}\right)\end{array}$ & $\begin{array}{c}\text { Induction frequency } \\
\text { of callus }(\%)\end{array}$ & $\begin{array}{c}\text { Transformation the } \\
\text { percentages in arcsin values }\end{array}$ \\
\hline 0.00 & 0.00 & $0.00 \pm 0.00$ \\
0.10 & 0.00 & $0.00 \pm 0.00$ \\
0.50 & 33.34 & $0.34 \pm 0.03 \mathrm{c}$ \\
1.00 & 64.67 & $0.70 \pm 0.02 \mathrm{a}$ \\
2.00 & 50.20 & $0.53 \pm 0.01 \mathrm{~b}$ \\
\hline
\end{tabular}

${ }^{\mathrm{z}}$ Explants of immature embryos were cultured on Murashige and Skoog basal medium supplemented with the different concentrations of 2,4-D. Data generated after $20 \mathrm{~d}$ in culture and were presented as the mean \pm SD. Different letters indicated that the values were significantly different at $P<0.05$ according to Duncan's multiple range test.

2,4-D $=2$,4-dichlorophenoxyacetic acid.

Table 2. Effect of active charcoal on callus induction from explants of immature embryos of Tapiscia sinensis. ${ }^{\mathrm{z}}$

\begin{tabular}{lccc}
\hline $\begin{array}{l}\text { Concn of 2,4-D } \\
\left(\mathrm{mg} \cdot \mathrm{L}^{-1}\right)\end{array}$ & $\begin{array}{c}\text { Concentrations of active } \\
\text { charcoal }(\%)\end{array}$ & $\begin{array}{c}\text { Induction frequency } \\
\text { of callus }(\%)\end{array}$ & $\begin{array}{c}\text { Transformation the } \\
\text { percentages in arcsin values }\end{array}$ \\
\hline 1.00 & 0.05 & 61.29 & $0.67 \pm 0.04 \mathrm{~d}$ \\
1.00 & 0.10 & 83.52 & $0.99 \pm 0.03 \mathrm{c}$ \\
1.00 & 0.50 & 100.00 & $1.57 \pm 0.00 \mathrm{a}$ \\
1.00 & 1.00 & 91.88 & $1.17 \pm 0.08 \mathrm{~b}$ \\
\hline
\end{tabular}

${ }^{\mathrm{z}}$ Explants of immature embryos were cultured on Murashige and Skoog basal medium supplemented with the different concentrations of active charcoal. Data generated after $20 \mathrm{~d}$ in culture and were presented as the mean $\pm \mathrm{SD}$. Different letters indicated that the values were significantly different at $P<0.05$ according to Duncan's multiple range test.

2,4-D = 2,4-dichlorophenoxyacetic acid.

their growth progressively stopped; there was not somatic embryogenesis after $40 \mathrm{~d}$ culture. However, the calli that had grown for 20 $\mathrm{d}$ were transferred to MS basal medium with different combinations of 6-BA and NAA, their color turned black, but after a growth pause of $\approx 13 \mathrm{~d}$, yellow somatic embryos emerged on the surface of the callus (Fig. 2A). After 19 d, globular-, heart-, torpedo-, and cotyledonary-stage embryos appeared (Fig. 2B-E). After $32 \mathrm{~d}$ growth, plantlets regenerated from these somatic embryos (Fig. 2F).

The effect of different combinations of 6-BA and NAA on embryogenesis in T. sinensis is shown in Table 3 . When 6-BA was maintained at $0.2 \mathrm{mg} \cdot \mathrm{L}^{-1}$, the embryogenesis rate rose first and then declined along with the NAA within a certain concentration range. The embryogenesis rate rose to $96.16 \%$ on the MS medium with 6-BA $\left(0.2 \mathrm{mg} \cdot \mathrm{L}^{-1}\right)$ and NAA $\left(0.05 \mathrm{mg} \cdot \mathrm{L}^{-1}\right)$. After subculture, somatic embryos grew quickly with a normal morphology. When only 6-BA was added to the medium, the embryogenesis rate was sharply reduced.

For callus multiplication, calli were transferred to solid MS basal medium supplemented with 6-BA $\left(0.2 \mathrm{mg} \cdot \mathrm{L}^{-1}\right)$, NAA $(0.05$ $\left.\mathrm{mg} \cdot \mathrm{L}^{-1}\right)$, activated charcoal $(0.5 \% \mathrm{w} / \mathrm{v})$, and different concentrations of sucrose. The results showed the sucrose had a significant impact on callus proliferation according to the observation after growing for $23 \mathrm{~d}$. At a concentration of $3 \%(\mathrm{w} / \mathrm{v})$ sucrose, a large number of embryos developed and the mass growth increased by 21 times in the 23-d subculture (Table 4). It was noted that embryos could not be differentiated on the sucrose-free culture medium, whereas higher concentrations were unfavorable for embryogenesis in $T$. sinensis. For example, on a medium with $9 \%(\mathrm{w} / \mathrm{v})$ sucrose, calli failed to differentiate

Once embryos reached the cotyledonary stage, they were transferred to a growth regulator-free medium for 4 weeks to allow them to further develop into plantlets. After 

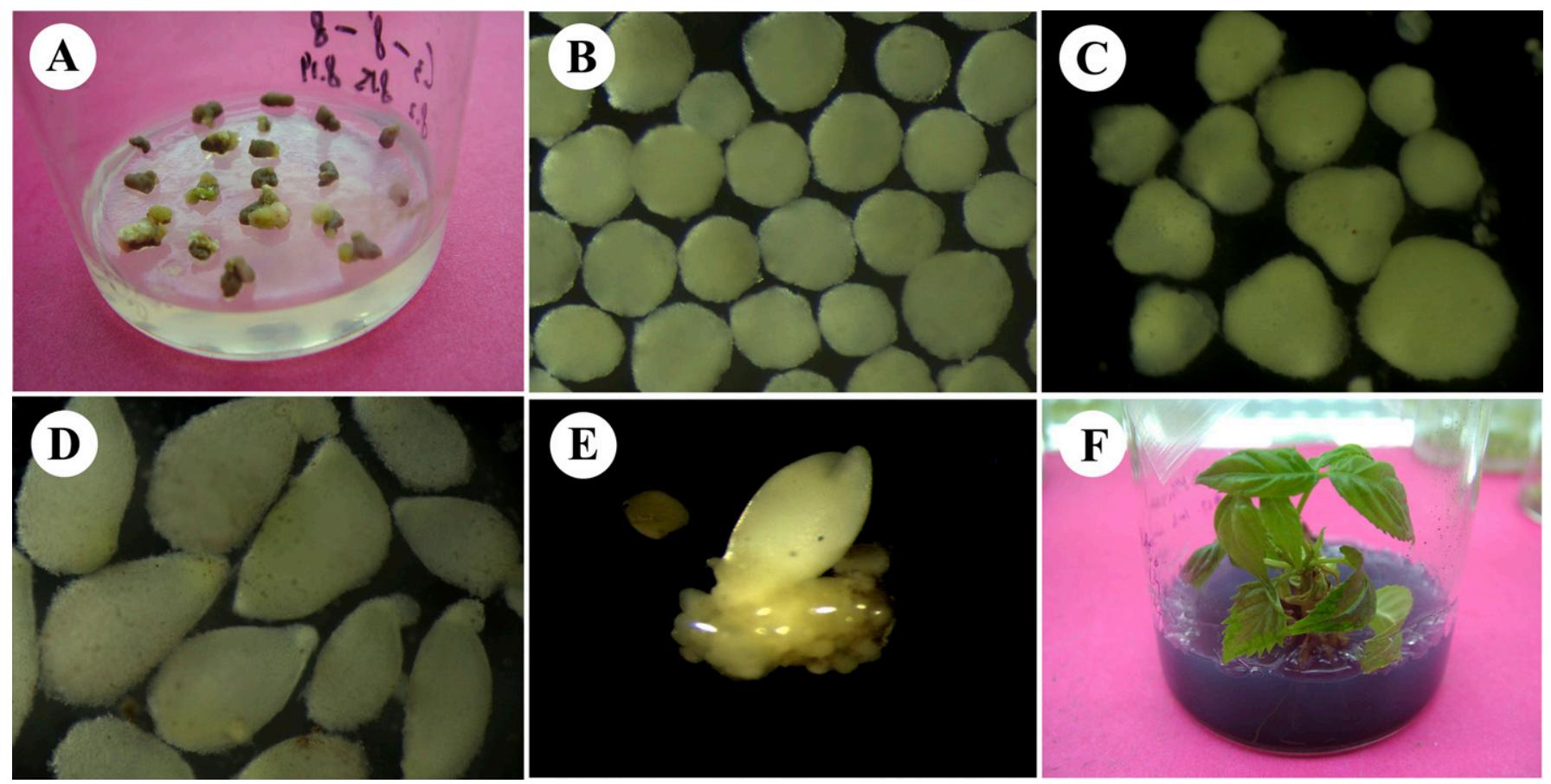

Fig. 2. Generation of somatic embryos and plant regeneration of Tapiscia sinensis. (A) Yellow embryogenic callus emerged from black callus. (B) Globular-stage embryos $(\times 63)$. (C) Heart-stage embryos $(\times 32)$. (D) Torpedo-stage embryos $(\times 32)$. (E) Cotyledonary-stage embryo $(\times 32)$. (F) Plants from somatic embryos.

Table 3. Effect of different combinations of growth regulators on somatic embryogenesis in Tapiscia sinensis. ${ }^{\mathrm{z}}$

\begin{tabular}{lccc}
\hline \multicolumn{2}{c}{$\begin{array}{c}\text { Concn of growth } \\
\text { regulators }\left(\mathrm{mg} \cdot \mathrm{L}^{-1}\right)\end{array}$} & $\begin{array}{c}\text { Frequency of somatic } \\
\text { embryogenesis }(\%)\end{array}$ & $\begin{array}{c}\text { Transformation the percentages } \\
\text { in arcsin values }\end{array}$ \\
\hline 6-BA & NAA & 16.51 & $0.17 \pm 0.18 \mathrm{~g}$ \\
0.10 & 0.00 & 46.46 & $0.48 \pm 0.09 \mathrm{f}$ \\
0.10 & 0.01 & 49.54 & $0.52 \pm 0.14 \mathrm{f}$ \\
0.10 & 0.05 & 40.66 & $0.42 \pm 0.11 \mathrm{f}$ \\
0.10 & 0.10 & 45.37 & $0.47 \pm 0.07 \mathrm{f}$ \\
0.10 & 0.50 & 19.33 & $0.19 \pm 0.04 \mathrm{~g}$ \\
0.20 & 0.00 & 70.60 & $0.78 \pm 0.05 \mathrm{de}$ \\
0.20 & 0.01 & 96.16 & $1.34 \pm 0.18 \mathrm{a}$ \\
0.20 & 0.05 & 89.08 & $1.10 \pm 0.03 \mathrm{~b}$ \\
0.20 & 0.10 & 81.17 & $0.95 \pm 0.06 \mathrm{bcd}$ \\
0.20 & 0.50 & 17.33 & $0.17 \pm 0.03 \mathrm{~g}$ \\
0.50 & 0.00 & 64.12 & $0.70 \pm 0.03 \mathrm{e}$ \\
0.50 & 0.01 & 85.44 & $1.03 \pm 0.04 \mathrm{~b}$ \\
0.50 & 0.05 & 82.48 & $0.97 \pm 0.04 \mathrm{bc}$ \\
0.50 & 0.10 & 66.83 & $0.73 \pm 0.07 \mathrm{e}$ \\
0.50 & 0.50 & 18.75 & $0.19 \pm 0.03 \mathrm{~g}$ \\
1.00 & 0.00 & 73.83 & $0.83 \pm 0.05 \mathrm{cde}$ \\
1.00 & 0.01 & 84.57 & $1.02 \pm 0.17 \mathrm{~b}$ \\
1.00 & 0.05 & 70.67 & $0.79 \pm 0.05 \mathrm{de}$ \\
1.00 & 0.10 & 81.30 & $0.96 \pm 0.16 \mathrm{bcd}$ \\
1.00 & 0.50 & &
\end{tabular}

${ }^{\mathrm{z}}$ Black calli were subcultured on Murashige and Skoog basal medium supplemented with the different combination of plant growth regulators. Data generated after $19 \mathrm{~d}$ in culture and were presented as the mean \pm SD. Different letters indicated that the values were significantly different at $P<0.05$ according to Duncan's multiple range test.

6-BA $=6$-benzylaminopurine; NAA $=$ naphthaleneacetic acid .

growing to a height of $10 \mathrm{~cm}$, the plantlets were removed from the culture flask and carefully washed in tap water to remove the traces of agar. These plantlets were planted in plastic cups in the greenhouse at $25 \pm 2{ }^{\circ} \mathrm{C}$ (relative humidity $60 \%$ ). When the plantlets grew to a height of $20 \mathrm{~cm}$ for 4 weeks, the seedlings were transferred to the field. Among the 100 seedlings developed from somatic embryos transferred to the field, 95 survived.
Histological observation. Cytohistological observations showed that the proembryos originated in two different ways in somatic embryogenesis of $T$. sinensis, one of which developed directly from the surface layer of explants of the immature embryos. There were many embryonic tissue protuberances (the red arrow labeling) under the epidermis (Fig. 3A). At the same time, some cells at the sub-epidermis divided and formed embryonic callus tissue after $5 \mathrm{~d}$ of culture with a large amount of starch grain (Fig. 3A). In another case, proembryos (the red arrow labeling) initiated from the surface layer or internally from the embryonic calli, which had abundant starch granules (Fig. 3B-C). Somatic embryos could not be initiated from the division of one single cell but were able to develop from a group of meristematic cells (Fig. 3D, the red arrow labeling).

Embryonic cells were always smaller in size than those of the parenchymatous cells with bigger nuclear and thicker plasma, some of which contained an abundance of starch grains. Given the morphological development of somatic embryos, which emerged from proembryos through globular-stage embryos, heartstage embryos, and torpedo-stage embryos, they finally developed into cotyledonarystage embryos with dramatic changes in synthesis ability and distribution of starch grains. At the early stages of embryonic calli, starch grains in cells began to accumulate. In some globular-stage embryos, all cells were full of starch grains (Fig. 3E, dye spot). However, this occurred only in cells of the surface layers rather than that of the entire body (Fig. 3F). At the later stage of globularstage embryos, starch grains (the red arrow labeling dye spot) had a polarized distribution in the embryo bodies (Fig. 3G). The ability to synthesize starch grains sharply decreased from the heart-stage embryos. At the period of torpedo-stage embryos and the early phase of the cotyledonary-stage embryos, starch grains only occurred in some cells of the peripheral region and provascular tissues (Fig. $3 \mathrm{H}-\mathrm{K}$, dye spot). Some secondary embryos (the red arrow labeling) formed on the surface of the heart-stage embryos (Fig. 3L). 


\section{Discussion}

Compared with mature embryos, immature embryos could induce callus and differentiate into somatic embryos. This result indicated that the type and physiological status of the explants were important factors affecting somatic embryogenesis in $T$. sinensis. Jain et al. (1995) also reported some difficulties in induction of calli from mature tissue of Picea abies, whereas juvenile tissues seemed more suitable. Other results indicated that zygotic embryos of cashew nut (Anacardium occidentale L.) at different developmental stages showed different potential for somatic embryogenesis (Gogate and Nadgauda, 2003). In further research, the relationship between the physiological-biochemical status of zygotic embryos and the induction of somatic embryos

should be investigated.

The role of 2,4-D in the induction of somatic embryos in the various systems is well established (George and Sherrington, 1984; Guo and Zhang, 2005). In our previous experiments it was also found that 2,4-D was an important plant growth regulator for the induction of somatic embryos. Somatic embryos could not be induced on media containing only NAA or indole-3-acetic acid, which was consistent with a number of previous reports in other species (Eapen and George, 1993; Gu et al., 2004; Guo and Zhang, 2005). The induction of somatic embryos in some species could only be achieved on a medium containing 2,4-D (Pareek and Kothari, 2003). However, 2,4-D would antagonize development and regeneration of somatic

Table 4. Effect of sucrose concentrations on somatic embryogenesis in Tapiscia sinensis. ${ }^{\mathrm{z}}$

\begin{tabular}{lccr}
\hline $\begin{array}{l}\text { Concn of } \\
\text { sucrose }(\%)\end{array}$ & $\begin{array}{c}\text { Inoculating } \\
\text { volume }(\mathrm{g})\end{array}$ & $\begin{array}{c}\text { Growth } \\
\text { volume }(\mathrm{g})\end{array}$ & Multiplication rate \\
\hline 0.00 & $0.87 \pm 0.06 \mathrm{a}$ & $1.07 \pm 0.05 \mathrm{~d}$ & $1.24 \pm 0.13 \mathrm{~d}$ \\
1.50 & $0.88 \pm 0.06 \mathrm{a}$ & $3.24 \pm 0.21 \mathrm{~cd}$ & $3.66 \pm 0.16 \mathrm{c}$ \\
3.00 & $0.88 \pm 0.05 \mathrm{a}$ & $18.68 \pm 0.49 \mathrm{a}$ & $21.33 \pm 0.88 \mathrm{a}$ \\
6.00 & $0.88 \pm 0.15 \mathrm{a}$ & $4.17 \pm 0.09 \mathrm{~b}$ & $4.72 \pm 0.18 \mathrm{~b}$ \\
9.00 & $0.89 \pm 0.03 \mathrm{a}$ & $3.71 \pm 0.09 \mathrm{c}$ & $4.19 \pm 0.22 \mathrm{bc}$ \\
\hline
\end{tabular}

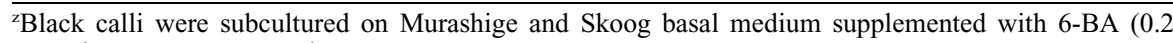
$\left.\mathrm{mg} \cdot \mathrm{L}^{-1}\right)$, NAA $\left(0.05 \mathrm{mg} \cdot \mathrm{L}^{-1}\right)$, active charcoal $(0.5 \%)$, and the different concentrations of sucrose. Different letters indicated that the values were significantly different at $P<0.05$ according to Duncan's multiple range test.

6-BA $=6$-benzylaminopurine; NAA $=$ naphthaleneacetic acid

embryos (Mao et al., 2012; Murashige, 1974). In our investigation, somatic embryos could be effectively induced on the medium with 2,4-D, but higher concentrations of 2,4-D would inhibit growth of the embryo, which also appeared in other species (Bai et al., 1998), and the growth of embryogenic callus progressively stopped after $13 \mathrm{~d}$ in culture. In Agave victoriae-reginae and $A$. vera-cruz, the presence of $2,4-\mathrm{D}$ was required in the medium for induction of somatic embryoids, but for their germination and development, a cytokinin was essential in place of 2,4-D (Martínez-Palacios et al., 2003; Tejavathi et al., 2007). Therefore, like in previous studies, a two-step culture was required for the completion of somatic embryogenesis in the present investigation. Although the presence of 2,4-D in the medium induced the embryogenic potential of the calli, cytokinin was required for the development of the somatic embryos in the subculture medium. In the present study, 6-BA was used to promote somatic embryogenesis. The embryogenesis rate rose to $96.16 \%$ on the conversion medium with 6-BA $\left(0.2 \mathrm{mg} \cdot \mathrm{L}^{-1}\right)$ combined with NAA $\left(0.05 \mathrm{mg} \cdot \mathrm{L}^{-1}\right)$.

Activated charcoal played a key role in embryogenesis of $T$. sinensis because it was capable of absorbing hazardous substances such as phenols, thus significantly increasing the induction rate and effectively preventing browning and stimulating the growth of the calli in Torreya grandis Fort. and Citrus
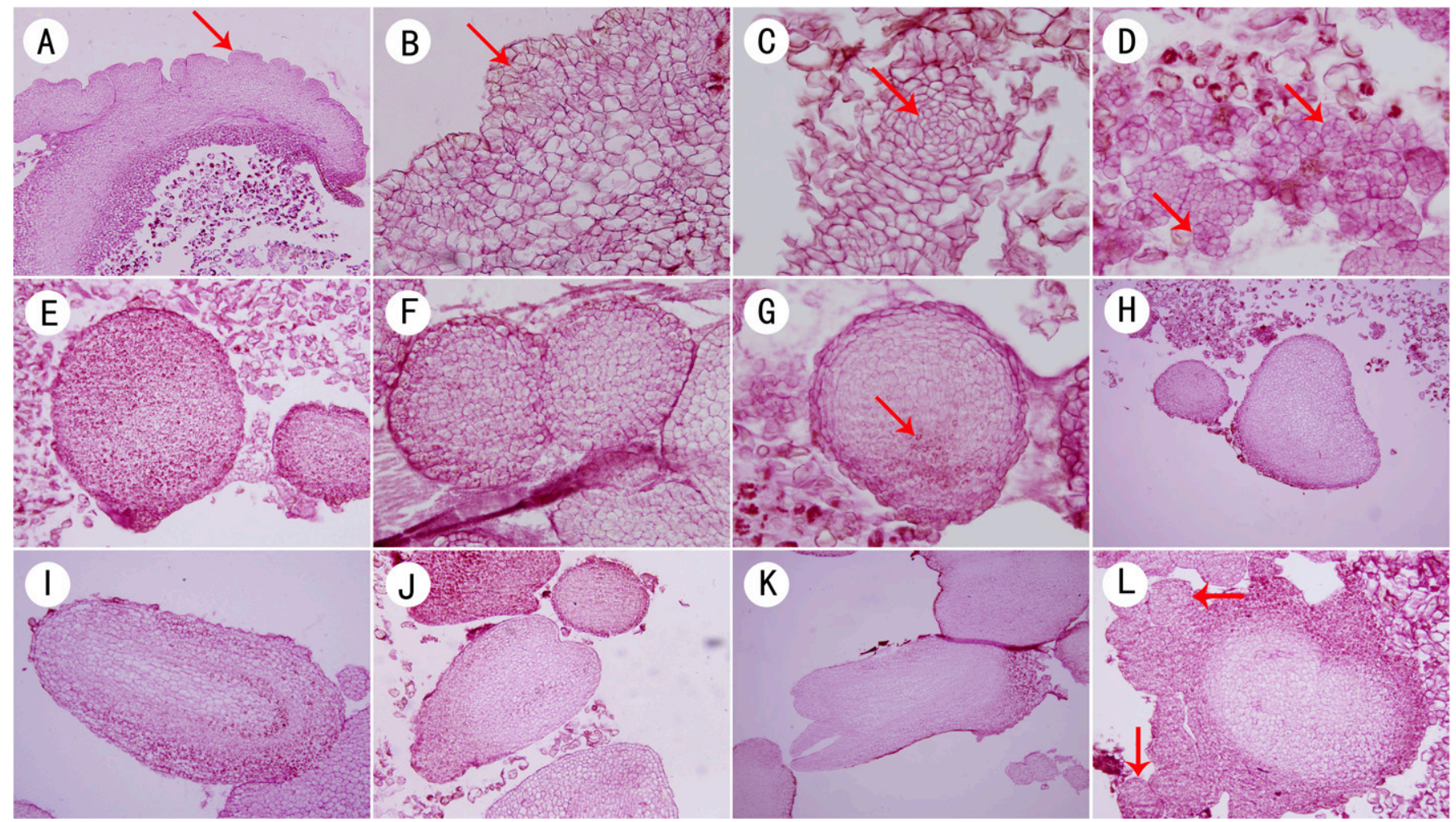

Fig. 3. Histological observation of somatic embryo development in Tapiscia sinensis. (A) Multicellular proembryos originated directly on the surface of explants of immature embryos $(\mathrm{bar}=500 \mu \mathrm{m})$. (B) Multicellular proembryos formed on the surface of embryonic calli (bar $=200 \mu \mathrm{m})$. (C) Proembryos stemmed from internal embryonic calli $(\mathrm{bar}=200 \mu \mathrm{m})$. (D) Multicellular proembryos inside embryonic calli $(\mathrm{bar}=200 \mu \mathrm{m})$. (E-F) Globular-stage embryos full of starch (bar $=200 \mu \mathrm{m}) .(\mathbf{G})$ Globular-stage embryo with a polarized distribution of starch (bar $=200 \mu \mathrm{m})$. $(\mathbf{H})$ Heart-stage embryo $(\mathrm{bar}=500 \mu \mathrm{m}) .(\mathbf{I})$ Torpedo-stage embryo $($ bar $=200 \mu \mathrm{m})$. $(\mathbf{J})$ Cotyledonary-stage embryo with two cotyledons $(\mathrm{bar}=200 \mu \mathrm{m}) .(\mathbf{K})$ Cotyledonary-stage embryo with four cotyledons $($ bar $=500$ $\mu \mathrm{m}) .(\mathbf{L})$ Secondary embryos developed from a heart-stage embryo $(\mathrm{bar}=200 \mu \mathrm{m})$. 
sinensis Osbeck. (Jiang and Chen, 2004; Liu et al., 2004). Other research also showed some relation between activated charcoal and embryos, which were induced (Agarwal et al., 2004).

Sucrose was used as a carbon source during the process of embryo growth and could also regulate osmotic potential (Park and Ahn, 2005; Wang et al., 2004). Concentrations of sucrose imposed significant effects on differentiation and proliferation of somatic embryos. The fastest differentiation and proliferation rate appeared with a culture medium containing 3\% (w/v) sucrose. Both higher concentrations $(9 \% \mathrm{w} / \mathrm{v})$ and insufficient $(0 \%$ or $1.5 \% \mathrm{w} / \mathrm{v})$ concentrations were not suitable for inducing somatic embryos. However, Lee et al.'s (2001) report showed that low concentrations $(0 \%$ and $1.5 \% \mathrm{w} / \mathrm{v})$ of sucrose showed a greater advantage in inducing somatic embryos of Daucus carota. However, Thomas' (2006) result showed that somatic embryos of Tylophora indica occurred more frequently under $200 \mathrm{mmol} \cdot \mathrm{L}^{-1}$ sucrose concentration (6.8\%). Park and Ahn (2005) also found that higher sucrose concentrations $\left(60 \mathrm{~g} \cdot \mathrm{L}^{-1}\right)$ were of benefit to embryogenesis in Eleutherococcus koreanum. Thus, we speculate that there are some differences in requirement of sugar concentration in different species' somatic embryogenesis.

Cytohistological observations illustrated that somatic embryos initiated from the surface layer of immature embryos. Division of epidermic cells of ground tissues at first formed calli, which appeared in various shapes with a large amount of starch granules, and then developed into somatic embryos. Somatic embryos could not be initiated from the division fission of one cell but only from a group of meristematic cells, which was in conformity with the report of Martíinez-Palacios et al. (2003). However, others stated that embryoids arose from a single cell (Tejavathi et al., 2000; Wang et al., 1990). Michaux-Ferriere et al. (1992) thought that the culture conditions favor unior multicellular modes of embryogenesis in callus with embryogenic potential. As mentioned, the origin of somatic embryos is still highly debated and needs further studies. At the same time, during the growth of somatic embryos, the peak of the starch granule disposition appeared at the embryonic callus and globular embryo period; this phenomenon may be an adaption dictated by the demand for energy during early phases of embryogenesis (Lin et al., 2000; Liu et al., 2004).

\section{Conclusion}

In vitro somatic embryo induction in $T$. sinensis was developed, which is a viable method for rapid propagation of this plant. The high somatic embryo induction and transplant survival rates suggest that this reproducible, affordable, and efficient in vitro plant regeneration protocol can be used for the conservation of this endemic and endangered plant.

\section{Literature Cited}

Agarwal, S., K. Kanwar, and D.R. Sharma. 2004. Factors affecting secondary somatic embryogenesis and embryo maturation in Morus alba L. Sci. Hort. 102:359-368.

Bai, S.X., L.Q. Liu, and W.L. Chen. 1998. Review on high quality somatic embryogenesis in artificial seed of plant. Journal of Agricultural University of He Bei 21:97-101.

Cheruvathur, M.K., N. Najeeb, and T.D. Thomas. 2013. In vitro propagation and conservation of Indian sarsaparilla, Hemidesmus indicus L. R. $\mathrm{Br}$. through somatic embryogenesis and synthetic seed production. Acta Physiol. Plant 35:771-779.

Eapen, S. and L. George. 1993. Somatic embryogenesis in peanut: Influence of growth regulators and sugars. Plant Cell Tissue Organ Cult. 35:151-156.

Fu, L.G. 1992. China plant red data book, rare and endangered plants. 1st Ed., Vol. 1. Science Press, Beijing, China.

George, E.F. and P.D. Sherrington. 1984. Plant propagation by tissue culture. Handbook and directory of commercial laboratories. Eastern Press, Berks, UK.

Gogate, S.S. and R.S. Nadgauda. 2003. Direct induction of somatic embryogenesis from immature zygotic embryo of cashewnut (Anacardium occidentale L.). Sci. Hort. 97:75-82.

Gu, Y.H., S.M. Gao, H.H. Guo, and F.L. Li. 2004 Somatic embryogenesis of Xanthoceras sorbifolia. Plant Physiology Communications 40:311-313.

Guo, Y.H. and Z.X. Zhang. 2005. Establishment and plant regeneration of somatic embryogenic cell suspension cultures of the Zingiber officinable Rosc. Sci. Hort. 107:90-96.

Han, T.S. 2010. Study on the cultivation technology and the annual growth rhythm of container seedlings of Tapiscia sinensis Oliv. Guizhou Forestry Science and Technology 38:18-20.

Jain, S.M., P.K. Gupta, and R.J. Newton. 1995. Somatic embryogenesis in woody plants. Vol. 2. Kluwer Academic Publishers, Dordrecht, The Netherlands.

Jiang, X.B. and L.G. Chen. 2004. Studies on the somatic embryogenesis of Torreya grandis. Acta Horticulturae Sinica 31:654-656.

Lee, E.K., D.Y. Cho, and W.Y. Soh. 2001. Enhanced production and germination of somatic embryos by temporary starvation in tissue cultures of Daucus carota. Plant Cell Rpt. 20:408-415.

Levin, R., V. Gaba, B. Tal, S. Harish, N.D. De, and I.K. Vasil. 1988. Automated plant tissue culture for mass propagation. Biotechnology 6:10351040.

Lin, R.S., Q.H. Wang, L.K. Liang, Q.S. Zheng, and X.H. Xiao. 2000. Somatic embryogenesis of peanut (Arachis hypogaea L.). Journal of Yantai
University 13:226-229 [Natural Science and Engineering edition].

Liu, H.Y., L.T. Xiao, X.D. Lu, and S. Wu. 2004. Studies on histocytology of somatic embryogenesis in Citrus sinensis cv. Valencia. Journal of Fruit Science 21:311-314.

Liu, W.Z., H.Q. Kang, H.C. Zheng, and Y.Z. Feng. 2008. An investigation on the sexual reproductive cycle in Tapiscia sinensis. Journal of Systematics and Evolution 46:175-182.

Mao, Y.S., Gui, X.Y. Jia, R.L. Xing, L. Li, P.D. $\mathrm{Wu}$, J. Ma, and G.Y. Xing. 2012. Efficient regeneration potential is closely related to auxin exposure time and catalase metabolism during the somatic embryogenesis of immature embryos in Triticum aestivum L. Mol. Biotechnol. 54:451-460.

Martínez-Palacios, A., M.P. Ortega-Larrocea, V.M. Chávez, and R. Bye. 2003. Somatic embryogenesis and organogenesis of Agave victoriaereginae: Considerations for its conservation. Plant Cell Tissue Organ Cult. 74:135-142.

Michaux-Ferriere, N., H. Grout, and M.P. Carron. 1992. Origin and ontogenesis of somatic embryos in Hevea brasiliensis (Euphorbiaceae). Amer. J. Bot. 79:174-180.

Murashige, T. 1974. Plant propagation through tissue cultures. Annu. Rev. Plant Physiol. Plant Mol. Biol. 25:135-165.

Murashige, T. and F. Skoog. 1962. A revised medium for rapid growth and bioassay with tobacco tissue culture. Physiol. Plant 15:473-497.

Pareek, A. and S.L. Kothari. 2003. Direct somatic embryogenesis and plant regeneration from leaf cultures of ornamental species of Dianthus. Sci. Hort. 98:449-459.

Park, S.Y. and J.K. Ahn. 2005. Mass production of Eleutherococcus koreanum plantlets via somatic embryogenesis from root cultures and accumulation of eleutherosides in regenerants. Plant Sci. 168:1221-1225.

Sun, Q.M. and X.J. Liu. 2004. Study on the germination of precious Tapiscia sinensis Oliv. Journal of Jiangsu Forestry Science \& Technology 31:12-14.

Tejavathi, D.H., G. Lakshmi Sita, and A.T. Sunita. 2000. Somatic embryogenesis in Flax. Plant Cell Tissue Organ Cult. 63:155-159.

Tejavathi, D.H., M.D. Rajanna, R. Sowmya, and K. Gayathramma. 2007. Induction of somatic embryos from cultures of Agave vera-cru z Mill. In Vitro Cell. Dev. Biol. Plant 43:423-428.

Thomas, D.T. 2006. Effect of sugars, gibberellic acid and abscisic acid on somatic embryogenesis in Tylophora indica (Burm. f.) Merrill. Chin. J. Biotechnol. 22:465-471.

Wang, L., B. Huang, M. He, and S. Hao. 1990. Somatic embryogenesis and its hormonal regulation in tissue cultures of Freesia refracta. Ann. Bot. (Lond.) 65:271-276.

Wang, X.C., S.Q. Liu, J. Ji, and P. Wang. 2004. The affect factors on the germination frequency of somatic embryos of soybean. Soybean Science 23:151-154

Zhou, Y.X. and X.P. Duan. 2008. Characteristics of dormancy and germination of Tapiscia sinensis Oliv. seeds. Journal of Beijing Forestry University 30:64-66. 